\title{
EL SÍNDROME DE ALIENACIÓN PARENTAL EN LA LEGISLACIÓN Y JURISPRUDENCIA NACIONAL
}

\section{THE PARENTAL ALIENATION SYNDROME IN NATIONAL LEGISLATION AND JURISPRUDENCE}

\author{
José Alfredo Pineda Gonzales \\ Docente \\ Universidad Nacional del Altiplano de Puno \\ alfredopinedag@gmail.com

\section{SUMARIO}

- Introducción

- Generalidades

- El Síndrome de Alienación Parental

- El Síndrome de Alienación Parental en la legislación nacional

- El Síndrome de Alienación Parental en la jurisprudencia nacional

- Conclusiones

\section{RESUMEN}

El Síndrome de Alienación Parental en el ámbito de la psicología y el derecho constituye un fenómeno que afecta la familia, la relación paterno y materno filial, la comunicación entre padres de hijos. La escaza literatura existente sobre el particular así lo refrenda, sin embargo, también existen estudios que le restan validez científica al Síndrome de Alienación Parental. En el ámbito de la legislación, la jurisprudencia y la casuística el fenómeno también aborda consideración poco uniforme. Los objetivos que se trazaron fueron: analizar el Síndrome de Alienación Parental en la legislación y jurisprudencia nacional, verificando si constituye una patología que afecta la comunicación de padres de hijos, generando afectación a los derechos de los niños y niñas; y si corresponde regular y sancionar el Síndrome de Alienación Parental para hacer prevalecer el interés superior de los niños y niñas. La metodología que se utilizó se verifica mediante el acopio y estudio de la legislación y de la jurisprudencia nacional sobre la patología del Síndrome de Alienación Parental, para ello se aplicó el método hermenéutico. La conclusión arribada, luego de que se analizó la legislación sobre el Síndrome de Alienación Parental, tanto a nivel constitucional como legal, asimismo la jurisprudencia nacional, es que no existe una legislación específica que prevenga y sancione dicha patología, sin embargo en la jurisprudencia nacional se la considera como caso justiciable, dado que afecta la comunicación e interrelación entre lo hijos con el padre o madre que no ejerce la tenencia, y con ello los derechos de dichos menores. Sin embargo, por sus efectos la alienación parental configura un caso de violencia psicológica, y por lo tanto es posible dictar medidas de protección y sanciones mediante el procedimiento establecido en la Ley $\mathrm{N}^{\circ} 30364$.

\section{ABSTRACT}

The Parental Alienation Syndrome in the field of psychology and law is a phenomenon that affects the family, the parental and maternal filial relationship, communication between parents of children. The lack of existing literature on the subject thus confirms it, however, there are also studies that detract from the scientific validity of the Parental Alienation Syndrome. In the field of legislation, jurisprudence and casuistry, the phenomenon also addresses uneven considerations. The objectives that were outlined were: to analyze the Parental Alienation Syndrome in the national legislation and jurisprudence, verifying if it constitutes a pathology that affects the communication of 
parents of children, generating affectation to the rights of the children; and if it is appropriate to regulate and sanction the Parental Alienation Syndrome in order to make the best interests of the children prevail. The methodology used was verified through the collection and study of legislation and national jurisprudence on the pathology of the Parental Alienation Syndrome, for which the hermeneutical method was applied. The conclusion reached, after the legislation on the Parental Alienation Syndrome was analyzed, both at the constitutional and legal levels, as well as the national jurisprudence, is that there is no specific legislation that prevents and sanctions said pathology, however in the national jurisprudence it is considered as a justiciable case, since it affects the communication and interrelation between the children with the father or mother who does not exercise the possession, and with it the rights of said minors. However, due to its effects, parental alienation constitutes a case of psychological violence, and therefore it is possible to dictate protection measures and sanctions through the procedure established in Law N 30364.

\section{PALABRAS CLAVES}

Alienación parental, relación paterno filial, derechos de los niños.

\section{KEYWORDS}

Parental alienation, filial parental relationship, rights of children.

\section{INTRODUCCIÓN}

La vida familiar constituye el escenario en que los niños, niñas y adolescentes pueden y deben desarrollarse integralmente. En ella los hijos menores de edad reciben protección, cuidados, atenciones, y afecto. El modelo de la familia nuclear representa el ideal de la familia de estos tiempos, los hijos viviendo con sus correspondientes padres. Sin embargo, cuando los padres se separan surge la necesidad de que alguno de los progenitores se encargue del cuidado de los hijos, y debe garantizarse que aquel progenitor que no ejerce la tenencia tenga posibilidad de vincularse permanentemente con sus hijos.

Cuando los canales de comunicación no fluyen de manera regular, por responsabilidad del progenitor que ejerce la tenencia, quien obstaculiza de diversas formas dicha comunicación mediante una campaña de desprestigio del progenitor que no ejerce la tenencia, a tal punto que provoque en el hijo menor de edad distanciamiento, desapego y hasta odio por dicho progenitor, se configura lo que la doctrina denomina el Síndrome de Alienación Parental. Tal patología no solamente afecta la estabilidad y equilibrio emocional del menor, sino que provoca mayor desintegración familiar, y afectación de los derechos del menor.

Este problema se inscribe en el área del Derecho Civil, y en la línea de investigación del Derecho de los niños, niñas y adolescentes. El propósito de la investigación es analizar la legislación y jurisprudencia nacional sobre el Síndrome de Alienación Parental para verificar el tratamiento jurídico de dicha patología, su prevención y sanción, si esta afecta la comunicación de padres e hijos, así como los derechos de los niños y niñas y si resulta necesario regular y sancionarlo. Así, se acopió la legislación y la jurisprudencia nacional vinculados al Síndrome de Alienación Parental, y se procedió a su análisis e interpretación.

\section{GENERALIDADES}

La familia constituye un instituto natural, que en el presente se configura como el punto de partida de la presente investigación. Así, en su concepción moderna puede ser considerada un régimen de relaciones sociales que se determina mediante pautas institucionalizadas relativas a la unión intersexual, la procreación y el parentesco. (Zannoni, 2002, pág. 3), sin embargo, evolucionando, ahora prevalece en este instituto natural, las relaciones socio afectivas que establecen nexos mucho más eficaces.

Se sostiene que las relaciones familiares se desarrollan generalmente en el ámbito doméstico, donde los integrantes de la familia interactúan cotidianamente, estableciéndose entre ellos relaciones diversas, con roles establecidos históricamente, desde la autoridad el pater familia del Derecho Romano que imponía un régimen autocrático, y donde el sometimiento de los integrantes de la familia se configuraba como parte de un proceso natural. Así, hemos considerado a la familia como un régimen de relaciones sociales institucionalizadas que son sancionados por el Derecho. (Zannoni, 2002, pág. 5) 
En tales relaciones, se canalizan construcciones socio afectivas necesarias para el desarrollo de los integrantes de la familia, y propiamente de los hijos, y éstas pueden ser decisivas en su desarrollo integral, permitiendo una crianza exitosa que con los años formará una persona sin mayores patologías o afecciones en su personalidad. Así, la comunicación entre padres e hijos resultan relevante, no solamente - como se dijo- para garantizar la construcción socio afectiva, sino además para garantizar la plena vigencia del derecho de los niños, niñas y adolescentes consagrada en la Convención sobre los Derechos de los Niños y en la legislación nacional.

Sin embargo, en las relaciones familiares a menudo se pueden advertir situaciones que perturban la normal comunicación, en especial cuando los padres se encuentran separados. Uno de estas situaciones que pueden alcanzar la condición de patología, es el Síndrome de Alienación Parental SPA, este se presenta como un trastorno en la etapa de la niñez, en el contexto de un conflicto por la tenencia y la custodia del hijo, y usualmente se manifiesta en una campaña de desacreditación del progenitor que no ejerce la tenencia. La finalidad que persigue es alejar al progenitor que no detenta la tenencia del entorno del niño.

Así, la alienación parental se presenta como una patología que obstaculiza las relaciones entre un niño o niña, en ocasiones adolescentes, con el progenitor o progenitora con el que no vive, con el que no ejerce la tenencia. Si bien este se desarrolla en el hogar y por la interacción del progenitor que ejerce la tenencia e inclusive con participación de la familia de éste, se aprecian con mayor nitidez en los Juzgados de Familia, en las disputas por la tenencia de sus hijos y el régimen de visitas. La alienación parental, conforme lo afirman los especialistas, causa daños psíquicos intensos en los niños y niñas, y afecta sus derechos a interrelacionarse con sus progenitores. Es necesario por tanto analizar dicha problemática en la legislación y jurisprudencia nacional.

\section{EL SÍNDROME DE ALIENACIÓN PARENTAL}

El Síndrome de Alienación Parental (SAP) es el desorden generado como consecuencia de las disputas entre los padres por la tenencia de los hijos. Se presenta cuando uno de los padres obstruye el vínculo de relación de su hijo con el progenitor, generalmente, no conviviente. (Varsi, 2012, pág. 384)

$\mathrm{Si}$ bien en la comunidad científica, la Organización Mundial de la Salud y sobre todo en la Asociación Americana de Psicología (APA) no existe consenso sobre su plena existencia. La definición del Síndrome de Alienación Parental, le corresponde a Richard Gardner. ${ }^{1}$

El síndrome de alienación parental (SAP) es un trastorno infantil que surge casi exclusivamente en el contexto de disputas por la custodia de los niños. Su manifestación primaria es la campaña de denigración del niño contra un padre, una campaña que no tiene justificación. Ello resulta de la combinación de una programación (lavado de cerebro) de adoctrinamiento parental y de las propias contribuciones del niño para el vilipendio del padre objetivo. Cuando un "maltrato/abuso sexual" está presente, la animosidad puede estar justificada y así la explicación del síndrome de alienación parental para la hostilidad del niño no es aplicable. (Gardner, 1991, pág. 14)

Es necesario aclarar que Gardner distinguió siempre entre el fenómeno de la alienación parental con el SAP. La primera se produce siempre que exista una campaña de difamación, pero con una buena terapia, el problema se soluciona. En la alienación parental el niño no interviene por sí mismo. En el SAP, sin embargo, el niño o niña es cómplice del progenitor alienador y crean sus propias teorías sobre porque deben odiar al progenitor alienado. (Torrealba, 2011, pág. 30)

Estas expresiones de la patología analizada generan diversas consecuencias en la vida familiar, en la relación paterno y materno filial, provocando conflictos diversos que suelen afectar derechos fundamentales de los niños y niñas. El tema es abordado desde diversas perspectivas, y no se alcanza aún consenso al respecto.

Así se tiene que dos son los enfoques existentes sobre el SAP: unos que lo consideran una enfermedad/trastorno y otros que lo consideran

\footnotetext{
1 La difusión y defensa del SAP fue la principal actividad intelectual de este autor. Su principal actividad pública fue como psiquiatra contratado en litigios por la custodia de los hijos.
} 
solamente una alteración de las conductas parentales. Es decir, los primeros lo aceptan y los segundos definitivamente no. Y dentro del SAP directamente debemos distinguir el Síndrome de la llamada AP (alienación parental) dependiendo si se cuenta o no con la ayuda del niño, niña o adolescente alienado. Las teorías o posiciones contrapuestas frente a la existencia del SAP, tienen que ver, en primer momento, con las doctrinas feministas, que discuten el sistema sexistas que implica que la legislación otorgue per se el cuidado personal o custodia de los hijos menores a las madres, sin que el padre sea considerado como una alternativa válida. El primer argumento que se ha esgrimido para desconocer el SAP como una enfermedad mental, es el hecho que no aparezca el denominado DSM IV (Diagnostic and Statistifical Manual of Mental Disorders) en su cuarta edición. ${ }^{2}$ Gardner se defiende estableciendo que los comités que elaboran el Manual son bastante conservadores para incluir nuevas enfermedades y requieren de muchos años de investigación (Torrealba, 2011).

La polémica se extiende no sólo en la duda de su existencia, sino aun en aquellos que lo admiten se postulan perspectivas claras y antagónicas, así como se escuchan voces que la apoyan incondicionalmente y afirman que se trata de una patología, también existen críticas a su condición de patología, y la niegan. Desde la mirada de la ciencia y la psicología en particular, la cuestión pasa por una discusión bastante encarnizada. Pero es indudable que algunas patologías, fenómenos o desordenes de orden psicológico no siempre deben estar catalogados como tales, pues es claro que otros focos de interés pueden ser objeto de atención clínica. (Mojica, 2014, pág. 20)

Desde el Derecho -sin embargo-, la discusión no es tan encarnizada, pues su utilidad para tomar decisiones a favor de la niñez y adolescencia, resulta sin duda evidente. Al operador del Derecho no le importa mucho la consideración de patología o no, le interesa más el procedimiento y los efectos de este en la niñez y adolescencia. Para Hoult, el Síndrome de Alienación Parental no debe ser entendido como un síndrome médico, sino uno de naturaleza legal (Hoult, 2006)

\footnotetext{
2 Este Manual es elaborado por la Asociación Americana de
} Psiquiatría.

\section{EL SÍNDROME DE ALIENACIÓN PARENTAL EN LA LEGISLACIÓN NACIONAL}

El Síndrome de Alienación Parental no se encuentra directamente regulada o sancionada en nuestra legislación, esa es una realidad que se verifica de la revisión de nuestra legislación vigente. Por lo tanto, existe un vacío normativo sobre la regulación jurídica de la alienación parental en nuestro país. (Espinoza, 2017, págs. 223-240)

\section{La Constitución Política del Estado}

Dada la naturaleza y finalidad de la Carta Política, no es posible encontrar en ella una legislación específica, sin embargo, nos permite sí identificar los derechos materia de afectación por el Síndrome de Alienación Parental.

Al efecto es importante centrar la atención en la norma contenida en el Artículo $1^{\circ}$, donde la persona humana asume un digno protagonismo. La dignidad es una condición o una cualidad de todo ser humano, es intrínseca a su ser espiritual. Desde su concepción la persona exige protección, y los otros son responsables ante ella, deben acogerla, promoverla y protegerla. Esto es imperativo en todas las etapas de su desarrollo, y con mayor énfasis en aquellas de mayor demanda, como la niñez, la adolescencia y la adultez mayor; así como en aquella que se determina por su condición de evidente vulnerabilidad.

Tal exigencia se hace específica en el caso de los hijos menores de edad, los cuales necesitan para su desarrollo integral- vinculaciones socio afectivas fundamentales, como es el necesario y constante contacto con sus progenitores, con su familia. Esto surge precisamente de la patria potestad que como conjunto de derechos y deberes que corresponde a los padres sobre la persona y el patrimonio de cada uno de sus hijos no emancipados (Vásquez, 1982, pág. 9). Garantizar esa vinculación conlleva sin duda alguna al respeto irrestricto de su dignidad.

Así lo ha entendido el Tribunal Constitucional al reconocer el derecho del niño a tener una familia, así el aludido tribunal sostiene que el derecho del niño a tener una familia, es un derecho constitucional implícito y que encuentra sustento en el principio-derecho de dignidad de la persona humana y en los derechos a la vida, 
a la identidad, a la integridad personal, al libre desarrollo de la personalidad y al bienestar reconocidos en los artículos $1^{\circ}$ y $2^{\circ}$, inciso 1 ) de la Constitución. (Cfr. STC 1817-2009-HC/ TC, fundamentos 14-15). (Jurisprudencia del Tribunal Constitucional, 2017). Tal elucubración jurídica no deja duda que el mejor escenario para el desarrollo integral de un menor de edad es sin duda su propia familia.

Tal norma se complementa a su vez con la contenida en el Artículo 2 de la propia Constitución, que consagra el derecho a la identidad de toda persona y al libre desarrollo de la personalidad. De igual forma el principio de protección de la familia contenido en el artículo $4 .^{3}$

Ahora bien, la aludida protección no solamente alude en abstracto a la familia, como institución, sino también a sus integrantes: padres e hijos. Del principio, se desprende además el derecho a la vida de familia, que implica - por ciertoel derecho a preservar y desarrollar relaciones familiares.

Del derecho a la vida familiar fluye a su vez, el derecho de los hijos a tener vinculación o contacto con sus progenitores. Pues si bien el estado ideal de la vida familiar es que los hijos vivan con ambos progenitores, en el caso que los progenitores se encuentren separados, corresponde en tal circunstancias que los hijos puedan tener contacto con cada uno de ellos, articulando para ello las instituciones de la tenencia compartida, y del régimen de visitas. En la misma línea encontramos el mandato de que la comunidad y el Estado protegen especialmente al niño, al adolescente (...), por ser etapas del desarrollo humano que ubican a la persona en un estado de evidente vulnerabilidad. La Constitución por ello postula y ordena su protección.

De ello se infiere que toda conducta, actividad o decisión que directa o indirectamente afecte los derechos de la niñez y adolescencia que agravien su dignidad, su identidad, su libre desarrollo, a vivir en un medio familiar, no solamente debe ser observado, reprochado y sancionado, sino que se debe articular un conjunto de medidas que prevengan dicha

3 "La comunidad y el Estado protegen especialmente a niño, al adolescente, a la madre y al anciano en situación de abandono. También protegen a la familia y promueven el matrimonio. Reconocen a estos últimos como institutos naturales y fundamentales de la sociedad". afectación. Tanto más que esta afectación provenga de los progenitores, pues su responsabilidad les impone que ellos deben realizar todo lo conducente para lograr el desenvolvimiento físico e intelectual de quien está sujeto a la patria potestad y, en caso de abandono, o descuido, el Estado podrá hacer cesar dicha patria potestad" ((Varsi, 2012, pág. 297)

En tal circunstancia, el Síndrome de Alienación Parental, que entre sus efectos genera una obstaculización de las relaciones parentales, configura un fenómeno que debe ser proscrito por incidir negativamente en el derecho a la vida familiar. Así, las restricciones al establecimiento armónico, continuo y solidario de las relaciones familiares vulneran el derecho a la familia, y afecta la plena satisfacción de los derechos de la niñez, que es la esencia del principio del interés superior del niño.

Concluyendo en esta parte se puede afirmar que la Constitución Política del Estado contiene normas importantes que protegen a la persona humana, a la familia y a la niñez, y que estas establecen un marco jurídico suficiente para prevenir y amparar toda situación de riesgo o de afectación de los derechos de los hijos menores de edad, en los cuales el Síndrome de Alienación Parental puede presentarse como una situación perniciosa.

\section{El Código de los Niños y Adolescentes}

Del análisis del Código de los Niños y Adolescentes no se aprecia un tratamiento o regulación del Síndrome de Alienación Parental, sin embargo de manera indirecta se puede inferir una regulación parcial y colateral, pues al consagrar una diversidad de derechos, niega al Síndrome de Alienación Parental como fuente generador de agravios a tales derechos de los niños, niñas y adolescentes.

Así, se tiene que la norma contenida en el artículo $84^{4}$ regula la facultad del juez para que en el caso de no existir acuerdo sobre la tenencia, en cualquiera de sus modalidades, este resuelva teniendo en cuenta lo siguiente:

\footnotetext{
4 a) El hijo deberá permanecer con el progenitor con quien convivió mayor tiempo, siempre que le sea favorable; b) el hijo menor de tres (3) años permanecerá con la madre; y c) para el que no obtenga la tenencia o custodia del niño, niña o adolescente debe señalarse un régimen de visitas. En cualquiera de los supuestos, el juez priorizará el En cualquiera de los supuestos, el juez priorizará el
otorgamiento de la tenencia o custodia a quien mejor garantice el derecho del niño, niña o adolescente a mantener contacto con el otro progenitor."
} 
Al establecer el criterio de priorización en el otorgamiento de la tenencia o custodia el Juez debe preferir al progenitor o progenitora que garantice el contacto del niño, niña $\mathrm{o}$ adolescente con el otro progenitor o progenitora que no detente la tenencia. La norma en cuestión busca proteger el derecho del niño, niña o adolescente de relacionarse o vincularse con quien no ejerce su tenencia. Así el régimen en cuestión busca afianzar los vínculos socio afectivos entre padres e hijos, sobre todo de aquel progenitor que no ejerce la tenencia, en buena cuenta fortalecer a la familia al margen que vivan juntos o no pues en un sentido propio y limitado la familia está constituida por el padre, la madre y los hijos (Borda, 1993, pág. 19)

Esta norma es la que más se aproxima a una cercana regulación preventiva del Síndrome de Alienación Parental, sin embargo, no impone propiamente una sanción frente a su perpetración, sino una preferencia entre ambos progenitores que permita que el progenitor que garantice mejor la comunicación de los hijos menores de edad, la asignación de la tenencia. Asimismo, queda claro que los conflictos conyugales no deben afectar nada o muy poco a las relaciones paternas y maternas filiales, las que deben mantenerse incólumes. Un doble vínculo de parentabilidad vigente y dinámico permite minimizar los efectos de la separación de los padres, pero para que esto pueda ser una realidad, es necesario que ambos progenitores mantengan un buen nivel de comunicación, y de trato cordial. Lo que no previene la alienación parental pues esta surge casi exclusivamente en el contexto de disputas por la custodia de los niños. (Gardner, 1991, pág. 14)

De no mantenerse tal estado, es muy probable que los efectos negativos los tengan que asumir los hijos. Pues en la realidad se aprecia que en ocasiones, el progenitor o progenitora que detenta la tenencia, no facilita el contacto del niño o niña con el otro progenitor o progenitora, o realiza acciones de obstaculización de dicho contacto y con ello afecta diversos derechos del niño o niña, lo que importa una afectación a lo prescrito en el artículo 3-A del Código de los Niños y Adolescentes. Pues es derecho de los niños y adolescentes el recibir un buen trato y afecto, por parte de los llamados a proveerle de tales valores. Precisamente el Síndrome de Alienación Parental se inscribe dentro de aquellas situaciones que configura una serie de conductas tendientes a aislar al otro progenitor y obstaculizar su relación con el hijo o hija menor de edad.

En esa línea, el artículo 4 del referido Código consagra el derecho de todo niño, niña y adolescente a su integridad personal. El niño y el adolescente tienen derecho a que se respete su integridad moral, psíquica y física y a su libre desarrollo y bienestar. No podrán ser sometidos a tortura, ni a trato cruel o degradante.

La norma citada establece un marco de protección al menor garantizando su integridad personal, en sus dimensiones moral, psíquica y física. El Síndrome de Alienación Parental precisamente afecta el libre desarrollo y bienestar de un menor pues incide en su integridad moral, psíquica y física al configurar una suerte de desorden psicológico caracterizado por una conducta permanente del hijo o hija que ataca, denigra o desvalora a un progenitor, por la influencia que al respecto ejerce el otro progenitor; su salud mental, su estabilidad emocional, y en ocasiones su esfera física, pues al obstaculizarse el contacto de padre o madre que no ejerce la tenencia con el menor éste no va a querer ver a dicho progenitor, salir con él, interactuar, construir socio afectividad, y progresivamente generará sentimientos de odio, rencor, frustración, animadversión que en resumen configuran un irrespeto por parte del progenitor alienante de los derechos del hijo alienado.

El Síndrome de Alienación Parental afecta la libertad del menor, pues no le permite determinar sus decisiones sin intervención e influencia del progenitor alienante. Si bien es cierto, las decisiones de un menor de edad deben ser orientadas, y en ocasiones conducidas por su responsable legal, cuando se le construye una realidad distinta fruto de la injerencia en la percepción que tiene el menor sobre el o la progenitora que no ejerce la tenencia, a quien se le presenta como defectuosa, mala o perversa, que no quiere al hijo, que prioriza otros asuntos antes que al propio hijo, etc., y tal campaña de desprestigio surte sus efectos cuando el menor decide no relacionarse con ese progenitor, cuando decide apartarse.

También se ve afectado el derecho a la identidad, consagrado en el artículo 5 del Código. Este implica forjar la identidad en el menor, y esa identidad se puede construir dinámicamente 
en las relaciones, comunicaciones y contacto del menor con el progenitor que no ejerce la tenencia. Es decir, el menor al tomar contacto con el progenitor que no ejerce la tenencia, vía régimen de visitas, va paulatinamente incorporando elementos como hábitos, costumbres, valores, percepciones que son ofrecidas o sugeridas por los padres, y esa incorporación va construyendo la identidad del menor. Si se obstaculiza la comunicación entre este menor y el progenitor que no ejerce la tenencia evidentemente se afecta el derecho a la identidad del menor, pues la figura (paterna o materna) no estará presente en su desarrollo psicosomático, y esa ausencia puede influir negativamente en su desarrollo integral.

El Código de los Niños y Adolescentes también consagra el derecho de un menor de edad a vivir en familia, así la norma contenida en el artículo $8^{5}$, y ello implica que aunque la familia se encuentre desintegrada, ello no debe ser una limitante para establecer lazos familiares continuos, pues ello favorece la formación integral del niño.

De la norma antes descrita se aprecia un precepto sumamente importante pues consagra el derecho natural que toda persona tiene, y más un en el caso de ser un menor de edad, que es de vivir en una familia.

En ese contexto, la alienación parental se relaciona también con la afectación al derecho y libertad de opinión, así la norma contenida en el artículo 9 del Código de los Niños y Adolescentes ${ }^{6}$ consagra el derecho a la libertad de opinión. De ello puede afirmarse que el aislamiento y distanciamiento del menor respecto de su progenitor que no detenta la tenencia, por influencia nefasta del progenitor que ejerce la tenencia impide al menor a formarse sus propios juicios y expresar libremente su opinión sobre la responsabilidad parental ejercida por sus progenitores.

5 El niño y el adolescente tienen derecho a vivir, crecer y desarrollarse en el seno de su familia. El niño y el adolescente que carecen de familia natural tienen derecho a crecer en un ambiente familiar adecuado. El niño y el adolescente no podrán ser separados de su familia sino por circunstancias especiales definidas en la ley y con la exclusiva finalidad de protegerlos. Los padres deben velar porque sus hijos reciban los cuidados necesarios para su adecuado desarrollo integral.

6 El niño y el adolescente que estuvieren en condiciones de formarse sus propios juicios tendrán derecho a expresar su opinión libremente en todos los asuntos que les afecten y por los medios que elijan, incluida la objeción de conciencia, y a que se tenga en cuenta sus opiniones en función de su edad y madurez.

\section{Legislación penal}

El Código Penal desarrolla a través del Título III los delitos contra la familia, estableciendo en su capítulo III la sección de delitos contra la patria potestad, sin embargo ningún tipo penal en particular alude al Síndrome de Alienación Parental.

Sin embargo, la búsqueda sistemática en nuestra legislación punitiva nos lleva a la Ley $\mathrm{n}^{\circ}$ 30364, "Ley para pervenir, sancionar y erradicar la violencia contra las mujeres y los integrantes del grupo familiar". Así se tiene que esta ley brinda protección a las mujeres durante todo su ciclo de vida: niña, adolescente, joven, adulta y adulta mayor, y a los integrantes del grupo familiar. Entendiendo como tales a los (...) descendientes.

La norma describe cuatro tipos de violencia, la violencia física, psicológica, sexual y patrimonial. La violencia psicológica es la que importa mayormente en este análisis, a esta se la entiende como la acción o conducta, tendiente a controlar o aislar a la persona contra su voluntad, a humillarla o avergonzarla y que puede ocasionar daños psíquicos ${ }^{7}$. Ello se traduce en el impedimento de uno de los progenitores a que el otro ejerza el derecho de relacionamiento con sus hijos. (Varsi, 2012, pág. 385)

En ese entender, las prácticas alienantes configuran sin duda una modalidad de violencia psicológica, pues impone una suerte de control en el comportamiento del menor. Asimismo imprime un aislamiento del menor respecto de su progenitor o progenitora que no tiene bajo su tenencia al referido menor. Ejercer control sobre el deambular del menor da forma al Síndrome de Alienación Parental, y sobre el particular corresponde afirmar también que dicha patología resulta muy dañina y por lo mismo corresponde su sanción por quien lo practica. Son muchos los ejemplos de hijos que no quieren salir con su progenitor o progenitora por las continuas desinformaciones proferidas por la progenitora o progenitor del menor que detenta la tenencia. Este tipo de conducta, dolosa en algunos casos contribuye busca un aislamiento del hijo alineado respecto de su otro progenitor o progenitora.

\footnotetext{
7 "Daño psíquico", es la afectación o alteración de algunas de las funciones mentales o capacidades de la persona, producida por un hecho o un conjunto de situaciones de violencia, que determina un menoscabo temporal o permanente, reversible o irreversible del funcionamiento integral previo.
} 
De esta forma, si bien no encontramos un tipo penal propio que describa a la alienación parental como conducta ilícita típica, es a través de la configuración del tipo penal de la violencia psicológica que se puede sancionar la conducta alienante. No obstante, es necesario considerar que mediante Decreto Legislativo 1323 del 05 de enero del año 2017 se introduce modificaciones al Código Penal precisamente en los tipos penales de lesiones vinculados a los actos de violencia contra la mujer y los integrantes del grupo familiar.

Así, se modifica en el artículo 121 del Código Penal el tipo de lesiones graves, donde se considera aquellas que causan a una persona una anomalía psíquica permanente. Las que infieren cualquier otro daño a la salud mental de una persona, o se determina un nivel grave o muy grave de daño psíquico. Considera además una agravante si la víctima es menor de edad. De igual forma se modifica el artículo 121-B considerándose en las circunstancias agravantes del tipo, cuando la víctima es menor de edad, cuando es descendiente por consanguinidad, y cuando la afectación psicológica se causa a los hijos o hijas, niños, niñas.

Como se aprecia en la normatividad penal referida, el Síndrome de Alienación Parental se adecua perfectamente a los tipos penales descritos, por lo tanto estas conductas, debidamente acreditadas pueden ser sancionadas con severidad, pues son calificadas como lesiones graves.

También, la norma aludida gradúa el daño psíquico, la afectación psicológica, cognitiva o conductual. Así el artículo 124-B del Código Penal establece que el daño psíquico es determinado a través de un examen pericial. La determinación de daño psíquico se subsume en el tipo penal de falta de lesiones leves, en tanto que cuando se determina un nivel moderado de daño psíquico tal resultado se subsume en el tipo penal de delito de lesiones, y cuando el resultado de la pericia califica en el nivel grave o muy grave de daño psíquico, los hechos se subsumen en el tipo penal de delito de lesiones graves. Ahora bien, cuando el resultado de la conducta psicológicamente dañosa no determina grado específico de daño psíquico, sea por la evaluación pericial o por cualquier otro medio probatorio idóneo y objetivo, el resultado califica como afectación psicológica, conductual o cognitiva.
Al margen de la consideración científica del Síndrome de Alienación Parental como patología, es evidente que su práctica genera efectos que se ponen en evidencia en el nivel psicosomático de la persona alienada. Si bien en algunos casos los efectos no son advertidos de manera clara, en la mayoría de casos son marcadamente visibles y se manifiestan en el área física o biológica, y sin duda alguna en la esfera psicológica produciendo una merma en el funcionamiento orgánico, en la actividad psíquica y social del menor alienado.

Sobre dichos efectos cita Bautista, que los efectos respecto de procesos psicológicos tales como la percepción, la motivación, las emociones, los sentimientos, las pasiones, el modo de referenciar la realidad desde una estructura cognitiva, Bautista, Gaitán y Moreno (1977) describen cómo múltiples factores influyen en las emociones, en las ilusiones, en el proyecto de vida mismo y cómo se ven afectados tales procesos por efecto del PAS ${ }^{8}$. (Bautista Casteblanco, 2007, pág. 68)

Como se aprecia de los tipos penales descritos, la alienación parental si bien no tiene un tipo penal específico, puede configurar afectación o daño psíquico, en los niveles de muy grave, grave, moderado o leve, y en tal circunstancia puede ser subsumido como falta si el nivel del daño psíquico es leve, y puede configurar delito si el daño psíquico es moderado, grave o muy grave. Por consiguiente, la alienación parental puede ser denunciada como acto de violencia psicológica, merecer medidas de protección y una sanción penal. Tal práctica, sin embargo, no es usual en nuestro medio, y ello determinado escasa casuística al respecto. En tal sentido, y como lo detalla el artículo 10 de la Ley $\mathrm{N}^{\circ} 30364$, las instituciones que conforman el Sistema Nacional para la Prevención, Sanción y Erradicación de la Violencia contra las Mujeres y los Integrantes del Grupo Familiar destinan recursos humanos especializados, logísticos y presupuestales con el objeto de detectar la violencia, atender a las víctimas, protegerlas y restablecer sus derechos.

En el caso que se interponga denuncia por actos de violencia psicológica en agravio de un menor de edad, por actos del progenitor que detenta la tenencia del mismo, y que

8 Siglas en inglés del Síndrome de Alienación Parental 
practica alienación parental con el propósito de controlar y aislar al menor del contacto con su otro progenitor, la Policía Nacional efectuará una sumarísima investigación en el plazo de 24 horas y elaborará un atestado o informe policial, el cual remitirá al Juzgado de Familia o el que haga sus veces, para que en el plazo máximo de setenta y dos horas, siguientes a la interposición de la denuncia, proceda a evaluar el caso y resolver en audiencia oral la emisión de las medidas de protección requeridas que sean necesarias. Asimismo, de oficio o a solicitud de la víctima, en la audiencia oral se pronuncia sobre medidas cautelares que resguardan pretensiones de alimentos, regímenes de visitas, tenencia, suspensión o extinción de la patria potestad, liquidación de régimen patrimonial y otros aspectos conexos que sean necesarios para garantizar el bienestar de las víctimas. Analizados los actuados, el juzgado de familia o su equivalente procede a remitir el caso a la fiscalía penal para el inicio del proceso penal conforme a las reglas del Código Procesal Penal, promulgado por el Decreto Legislativo 957.

En el caso particular de la violencia psicológica proveniente de casos de alienación parental, las medidas de protección no solamente estarán vinculadas al cese de los actos de alienación parental, es decir a la prohibición de que el progenitor alienante continúe con su campaña de desinformación, aislamiento e incomunicación con su menor hijo, bajo apercibimiento que de no hacerlo y persistir en dicha conducta se le denuncie por la comisión del delito de desobediencia a la autoridad. Al efecto será necesario nueva denuncia que demuestre la persistencia en dichos actos, asimismo nueva evaluación psicológica que demuestre que la alienación parental no se ha remitido y continua en el menor. Asimismo, será necesario dictar medidas cautelares de fijación de un régimen de visitas (en el caso que no se hubiera acordado por ambos progenitores o fijado judicialmente), con intervención inclusive del equipo multidisciplinario del Juzgado, y también la suspensión de la patria potestad por maltrato mental, conforme a lo que regula el artículo 83 del Código de los Niños y Adolescentes.

Como se puede apreciar, la ausencia de una legislación penal específica no impide o restringe los mecanismos de protección y sanción frente a casos de alienación parental, en esta situación se debe recurrir a las normas contenidas en la Ley 30364 y al Decreto Legislativo $\mathrm{N}^{\circ} 1323$, donde vía el proceso de violencia psicológica se pueden atender dichos casos.

\section{EL SÍNDROME DE ALIENACIÓN PARENTAL EN LA JURISPRUDENCIA}

Una primera impresión que se tiene, cuando en el ámbito judicial se alude a este tema, es que todavía resulta incipiente la casuística que se tiene al respecto. No se aprecia, por cierto, una sistematización de casos, pues es altamente probable que en los Juzgados de Familia a nivel nacional se tengan muchos casos, pero que no llegan a instancias de la Corte Suprema. Por lo que se ha procedido a registrar los siguientes casos específicos.

\section{Casación $N^{\circ}$ 2067-2010-Tenencia/Lima}

La sentencia casatoria ${ }^{9}$ se origina en relación al fallo emitido por la Sala Civil de la Corte Superior de Justicia de Lima, sobre el proceso acumulado de tenencia expediente $\mathrm{N}^{\circ} 183516$ 2007-22 iniciado por Gerardo Antonio Rosales Rodríguez y el expediente $\mathrm{N}^{\circ}$ 183507-200778 iniciado por María Meier Gallegos. En dicho proceso acumulado la Sala Superior Civil otorga la tenencia y custodia de los niños Elizabeth Valeria y Gerardo Antonio Rosales Meier a doña María Elena Meier Gallegos donde se determina que la naturaleza y origen de los problemas familiares que llevaron a la separación de los cónyuges y la conducta del padre de separar a la madre de sus hijos son las diversas agresiones, tanto físicas como psicológicas padecidas por la cónyuge; y la violencia física y psicológica realizados por el progenitor.

Se trata de un supuesto de Síndrome de Alienación Parental provocado por el padre y la familia paterna, que se refleja en la conducta irrespetuosa de los hijos frente a su madre, por lo cual se dispone que ésta ejerza la tenencia a fin de restablecer el vínculo materno filial resquebrajado, lo que redundaría en interés de los hijos pese a la opinión contraria de estos. Hasta aquí el encuadre en el supuesto clásico: incluso la solución se adecua a lo propuesto por Gardner, esto es de obligar a la aceptación de la

9 Publicada en el Diario Oficial El Peruano el 1 de setiembre del 2011 
progenitora rechazada. Lo que hace de este caso especial radica en que existen imputaciones de abuso sexual, pero estas recaen sobre el propio alienador y no sobre la progenitora rechazada.

Es claro que la medida de protección dictada a favor de la madre rechazada, que inclusive contradice el propio deseo de los menores de continuar bajo la tenencia de su progenitor, resulta necesaria para que se restablezca la relación materno filial, tan necesaria en la formación integral de un menor de edad, y como mecanismo además para evitar la continuidad de la práctica alienante.

\section{Sentencia expediente $\mathrm{N}^{\circ}$ 00972-2012- Reconocimiento de tenencia/Huaura}

Se trata de un caso de reconocimiento de custodia y tenencia de una niña de dos años y cinco meses de edad. Sentencia expedida por la Sala Mixta de la Corte Superior de Justicia de Huaura, su fecha quince de setiembre de dos mil catorce.

La aludida sentencia señala en sus antecedentes que mediante escrito que corre de fojas 27 a 36, don Joel Milton Fernández Murga, interpone la demanda contra Laura Leaño Guerra, a fin de que se le reconozca su derecho de custodia y tenencia sobre su menor hija IEFL de dos años y cinco meses de edad. (...) 2.3. El Juzgado de Familia de Huaura declara fundada en parte la demanda al considerar que el resultado pericial efectuado a la menor permite colegir la intención consciente o inconsciente del demandante de borrar o menoscabar la figura materna de la demandada suplantándola con la de su actual conviviente, y conforme se ha indicado en el escrito de contestación, puede ejercer la tenencia de la menor en forma compartida con la demandante, los fines de semana. 2.4. La demandada al apelar sostiene que, no se ha tenido en cuenta el interés superior de su hija, al disponerse la tenencia compartida, situación con el que no se encuentra conforme al advertirse que la menor no la reconozca como su madre, razón por la que, debe corresponderle la tenencia absoluta fijándose un régimen de visitas para el padre". (Diálogo con la jurisprudencia, 2015, págs. 133-134)

Como se puede advertir la ratio decidendi de la sentencia de primera instancia gira en torno a los resultados de la pericia psicológica, pues en base a dichos resultados se dispone la tenencia compartida y el correspondiente tratamiento psicológico.

Del fundamento antes expuesto se puede apreciar de manera meridiana que el progenitor de la menor, en la convivencia cotidiana ha venido influyendo en la menor para los efectos de que ésta sea desplazada por su nueva pareja, a quien su menor hija le dice mamá, y ante tal situación no realiza ninguna aclaración. Precisamente tal conducta del progenitor se inscribe en el denominado Síndrome de Alienación Parental, pues la campaña del progenitor va dirigido a desplazar la figura materna (de la madre biológica) por una nueva figura materna (su actual pareja), permitiendo que la menor sea sumida en el error, y adopte una relación materno filial ficticia.

La actividad alienante del progenitor no sólo se dirigía a aislar a la menor de su progenitora, sino que además a sustituirla por su nueva pareja sentimental. Situación que lo iba logrando pues la menor, por lo precoz de su edad, venía identificado a dicha persona como su progenitora, lo que evidentemente afectaba el derecho a la identidad de la respectiva menor. Por ello se justifica plenamente la decisión judicial, pues esta es restitutoria de los derechos afectados.

\section{Casación $\mathrm{N}^{\circ}$ 5138-2010-Tenencia/Lima}

Se trata de la resolución casatoria de fecha 31 de agosto de 2011 expedida por la Sala Civil Transitoria de la Corte Suprema de Justicia de la República. El caso es un proceso acumulado de Tenencia y Custodia de Menor en el que ambos progenitores interpusieron demanda solicitando la tenencia y custodia de sus menores hijas NNN y CCC. El Juez de la causa mediante sentencia de primera instancia de fecha veinticinco de junio del año dos mil diez ha declarado fundada la demanda de Tenencia y Custodia solicitada por Renzo Miguel Beteta Valderrama e infundada la misma pretensión solicitada por Valeria Andrea Furno Ferro, concediendo la tenencia de las menores a favor del padre y ordenando que la demandada cumpla en el plazo de veinticuatro horas con entregar en el hogar paterno a las citadas menores, concediéndole además un régimen de visitas a la madre y ordenando que las partes continúen terapias que les ayuden en su personalidad a fin de recuperar la confianza $\mathrm{y}$ en procura de que las niñas tengan una buena interrelación familiar. 
De los fundamentos de dicha sentencia se concluye que la madre no se encuentra prestando colaboración para que la interrelación del padre con sus hijas se efectivice, además de no estar contribuyendo ni estar garantizando el vínculo con el padre, existiendo por el contrario indicadores que la hija mayor se encontraría afectada del Síndrome de Alienación Parental ejercida por la madre en contra del padre. Apelada la sentencia dictada en primera instancia, la Sala Superior mediante resolución de fecha dieciocho de octubre del año dos mil diez la confirma.

En primera instancia se llegó a la conclusión de que existía Síndrome de Alienación Parental ejercido por la madre en contra del padre, sobre la base de los informes psicológicos y psiquiátricos realizados a las partes y a las menores hijas y de los informes sociales de los padres y que la madre no prestaba su colaboración para la interrelación del padre con sus hijas. Así, se observó que en un comienzo la hija mayor presentaba una relación normal con el padre, lo que cambió al obtener la madre la tenencia provisional. Lo que ponía en evidencia que en la tenencia ejercida por la progenitora, ésta desarrolló actividades alienantes en sus menores hijas generando obstáculos para la relación entre tales menores y su progenitor.

Al resolver la apelación, la Sala Superior agrega como datos relevantes el hecho de que la madre varió de domicilio sin informar al juzgado y que existe un proceso en contra de la madre por restitución internacional del hijo que tuvo con otra pareja, habiéndose oficiado a la Policía Nacional para la búsqueda y ubicación de la demandada. Tal aporte al supuesto fáctico del caso en concreto ayuda a formarse convicción del carácter alienante de la progenitora.

La Corte Suprema agrega que de la evaluación psicológica no se verifica indicio de comportamiento agresivo del padre, que el régimen de visitas otorgado a su favor no se pudo cumplir por falta de colaboración de la madre, y que si bien en un principio la hija mayor se identificaba con ambos padres, luego de que la madre obtuvo provisionalmente la tenencia, se advirtió una reacción y conducta distinta para con el padre, por la influencia negativa que había ejercido la progenitora.

\section{Sentencia Expediente $N^{\circ}$ 00075-2012- Tenencia/Ica}

Fallo emitido por la Segunda Sala Civil de Ica, su fecha trece de marzo de 2013. La sentencia in comento, se origina por la demanda interpuesta por la progenitora del menor J.L.M.E. a favor de quien se dispone la tenencia solicitada y fija un régimen de visitas a favor del progenitor. En la sentencia se establece que el menor J.L.M.E., bajo el cuidado de su padre, viene siendo afectado en sus derechos previstos en los artículos 6 y 8 del Código de los Niños y Adolescentes, consistentes en derecho al libre desarrollo de su personalidad, a mantener sus relaciones familiares con ambos progenitores y a gozar en un ambiente equilibrado de paz y estabilidad, pus el menor no vive permanentemente con el padre, sino con el abuelo y con una tía, y el padre sólo lo ve los fines de semana. En el Informe Psicológico que obra en el expediente se ha concluido que se observa emocionalmente un niño con un cimentado Síndrome de Alienación Parental, de negatividad al cariño de su madre (...) de forma consciente y posteriormente inconsciente el padre y demás familiares paterno alienadores han y están logrando que el niño desvalorice, desprecie la presencia y el acercamiento de su madre.

Importante sentencia, en un caso donde resulta evidente la existencia del Síndrome de Alienación Parental, por diagnóstico psicológico especializado. También es importante la conclusión arribada por el colegiado, pues considera al SAP como una forma de maltrato infantil, lo que daría la configuración de violencia infantil (violencia contra un integrante del grupo familiar), y por lo mismo justiciable en la vía penal.

El juez de primera instancia declaró infundada la demanda a partir de la valoración del peritaje psicológico practicado al menor y a su progenitor, informe en el cual se acreditó que el menor sufría de síndrome de alienación parental. Ante esta decisión, que le era desfavorable, el progenitor impugnó tal decisión vía recurso de apelación.

Los jueces superiores, absolviendo el grado, realizaron un detallado análisis de todos los medios probatorios; y se acreditó que el menor padecía del Síndrome de Alienación Parental. Esta conclusión sirvió para que la Sala Civil 
determine que el menor alienado no podía continuar con su progenitor y que resultaba necesario que reciba un tratamiento psicológico para restablecer su salud psicológica. Asimismo, se ordenó que el menor deba ser cuidado por su otro progenitor con el fin de garantizar su salud mental, así como también se dispuso que los padres se sometan a terapias psicológicas y charlas de orientación.

\section{Casación $N^{\circ}$ 5008-2013-Régimen de visitas/Lima}

Se trata de la sentencia del seis de agosto de dos mil catorce, expedida por la Sala Civil Transitoria de la Corte Suprema de Justicia de la República ${ }^{10}$. La presente resolución también resulta útil para analizar el fenómeno de la alienación parental, de su análisis se tiene Liliana Paola Tenorio Gallardo interpone demanda de Variación de Régimen de Visitas establecido para su menor hijo de iniciales J.P.D.T. (10 años de edad). La sentencia de primera instancia declaró infundada la demanda interpuesta, señalando que de la evaluación psicológica el menor muestra rechazo y la resistencia que muestra por establecer contacto con su padre sin la presencia de la madre, resulta incompatible con su edad, advirtiéndose más bien que corresponde a la influencia de las actitudes maternas pues esta última no muestra una conducta que favorezca a la relación paterno filial y ello se traduce en el incumplimiento del régimen de visitas.

La Sala Superior mediante sentencia de vista de fecha dieciocho de noviembre de dos mil trece, confirma la sentencia que declara infundada la demanda pues considera la necesidad del menor, dada su edad, de mantener una relación paterno filial que asegure su desarrollo, así como el deseo del demandado de mantener contacto directo con el niño; considerando además que las condiciones en las que se pretende modificar el régimen de visitas no contribuiría a la formación psicoemocional del menor, por cuanto de ellas se advierte la permanente intervención de la madre o su entorno familiar, impidiendo con ello una comunicación entre el padre y el hijo.

Interesante sentencia que pone en evidencia la instrumentalización del régimen de visitas a los hijos menores de edad para los efectos

10 Publicada en el Diario Oficial El Peruano el 30 de octubre del 2014. de lograr una represalia contra la ex pareja, tal conducta conlleva la alienación del hijo, basada en una campaña constante para poner al hijo en contra del padre y de la nueva familia de este. Buena decisión judicial además que dispone el cumplimiento del régimen de visitas para no cortar la relación paterno filial.

\section{Casación $N^{\circ}$ 3767-2015- Tenencia/ Cusco}

La Sala Civil Transitoria de la Corte Suprema nos proporciona una interesante resolución, que se inscribe en la casuística sobre el Síndrome de Alienación parental ${ }^{11}$.

El resumen de la aludida resolución casatoria establece que no puede concederse una tenencia compartida a favor de ambos padres si la colaboración y coordinación constante que se necesita de parte de ambos no es posible debido a los indicios de alienación parental; puesto que la conducta negativa o confrontacional de uno ellos pondría en mayor riesgo la integridad emocional y física del niño, niña y adolescente.

Los hechos del presente caso corresponden a la madre de un niño de tres años quien demanda la tenencia y custodia del menor, debido a que el padre del niño se lo había arrebatado, llevándoselo sin su consentimiento a otra ciudad, de forma tal que no le permitía tener ningún contacto con él. El demandado, padre del menor, al absolver el traslado y contestar la demanda señaló que decidió llevarse al niño debido al aparente estado de abandono en que lo tenía su progenitora, que ponía en riesgo su integridad física, máxime si ella venía siendo víctima de violencia familiar por su ex pareja.

Ambas instancias ampararon la demanda (tenencia exclusiva) y dispusieron la entrega inmediata del niño a la madre. Tomaron en cuenta los informes psicológicos y sociales que determinaban que el actual ambiente donde vivía el niño no era adecuado para el desarrollo de su personalidad, pues su padre se mostraba inestable emocionalmente y presentaba conductas inapropiadas y venía manipulándolo para contrariar a su progenitora, lo que ponía en evidencia el Síndrome de Alienación Parental.

El padre recurre en casación, y los magistrados de la Corte Suprema declararon fundado

11 Publicada en el Diario Oficial El Peruano el 2 de octubre del 2017. 
en parte el recurso solo para establecer que la entrega del niño, en caso de tenencia monoparental (exclusiva), debe ser progresiva con ayuda del equipo multidisciplinario a fin de no le producir ningún daño o trastorno al menor.

Por otro lado, precisaron que no sólo existe un sistema monoparental de tenencia sino uno de tenencia compartida, el mismo que no podía ser concedido cuando existan indicios de alienación parental que impidan la convivencia con ambos padres, por cuanto la conducta negativa y confrontacional de uno de ellos impide la colaboración de ambos, poniendo en riesgo la integridad emocional y física de los hijos.

Como balance debe afirmarse que la revisión $\mathrm{y}$ análisis de los casos judiciales y de la jurisprudencia nacional demuestran que existen suficiente evidencia de que tal fenómeno o patología existe en una manifestación concreta.

Estos casos acontecen en las familias desintegradas, con padres separados, y que al no ponerse de acuerdo en cuanto al ejercicio de la tenencia de los hijos se ve envuelta en sendos procesos judiciales de tenencia, reconocimiento de tenencia, régimen de visitas y otras acciones concomitantes. En todos los casos, la evidencia del SAP no lo encontramos sólo en una construcción argumentativa sino mediante pericias psicológicas realizadas en niños o niñas. Por lo tanto podemos afirmar que existe evidencia científica de su existencia y que no se trata solamente de una elucubración teórica.

Son casos de naturaleza civil, que se ventilan en Juzgados Especializados de Familia, que en algunos casos llegan hasta la Corte Suprema mediante el recurso de casación. La resolución final, en cada caso, no solamente se pronuncia por la estimación o desestimación de la pretensión, sino que además pone en evidencia la afectación o vulneración de derechos de los niños y niñas. Sin embargo, en ningún caso tal situación ha permitido que el caso se derive a la instancia penal para los efectos de la sanción. Lo curioso es que quien vulnera derechos de los hijos menores de edad, es el propio progenitor que detenta la tenencia.

\section{CONCLUSIONES}

El Síndrome de Alienación Parental constituye una patología o fenómeno de dimensión psíquica que se caracteriza por la acción de uno de los progenitores que detenta la tenencia del hijo menor de edad y que se traduce en una campaña sostenida basada en desinformación o información a menudo falsa sobre el pensar $\mathrm{y}$ actuar del progenitor que no vive con el hijo, con el propósito de buscar que el niño o niña alienada internalice tales calificativos y calidades de su otro progenitor, provocando en el hijo alienado animadversión y nulo deseo de verlo, de dialogar e interactuar con él.

El Síndrome de Alienación Parental, por los efectos que genera, afecta los derechos de los niños y niñas pues al obstaculizar la comunicación y relación entre estos y el progenitor que no ejerce la tenencia, se genera la afectación a los derechos al respeto de su dignidad, a su integridad moral y psíquica, a su identidad, a su libre desarrollo y bienestar, a ser protegido por la comunidad y el estado, y a realizar vida familiar, tal como se comprueba de los casos judiciales analizados mediante jurisprudencia en procesos de tenencia $\mathrm{y}$ régimen de visitas.

No existe en nuestra legislación nacional normas específicas que prevengan y sancionen los actos de alienación parental, la jurisprudencia no integra dicho vacío, sin embargo se aprecia de la norma contenida en el artículo 85 del Código de los Niños y Adolescentes una suerte de sanción civil al progenitor que no garantice la comunicación entre el hijo y el progenitor que no va a detentar la tenencia. $\mathrm{Y}$ en cuanto a las normas punitivas, en los casos de alienación parental se puede acudir a la figura penal de la violencia contra la mujer o los integrantes del grupo familiar, en su versión de violencia psíquica para que se dicte a favor del menor alienado medidas de protección, medidas cautelares y en contra del progenitor agresor una sanción penal. Por lo tanto, no resulta imprescindible una legislación específica para sancionar los casos de alienación parental, tanto más que en la comunidad científica no existe consenso sobre la naturaleza patológica del referido síndrome. 


\section{FUENTES DE INFORMACIÓN}

\section{Fuentes bibliográficas}

Borda, Guillermo. (1993). Manual de Derecho de Familia. Buenos Aires, Argentina: Perrot.

Diálogo con la jurisprudencia (2015). Corte Superior de Justicia de Huaura considera que suplantación de figura materna constituye alienación parental. Lima, Perú: Gaceta Jurídica.

Gardner, Ricard. (1991). Legal and Psychaterapeutic Aproaches to the tree og parental alienation Syndrome Familiaes. Columbia. Court Review.

Mojica, Lady (2014) Protección de niñas, niños y adolescentes en caso de alienación parental y debilitamiento de las de las relaciones parento filiales. Bogotá, Colombia: Universidad Nacional de Colombia.

Torrealva, Alfredo (2011) El Síndrome de Alienación Parental en la legislación de familia. Santiago de Chile, Chile: Universidad de Chile.

Varsi, Enrique (2012) Tratado de Derecho de Familia. Lima, Perú: Editorial Gaceta Jurídica.

Vásquez, José Castan (1982) La Patria Potestad como función en el nuevo derecho de familia. Madrid, España: Documentación Jurídica.
Zannoni, Eduardo. (2002) Derecho de Familia. Buenos Aires, Argentina: Astrea.

\section{Fuentes electrónicas}

Bautista Casteblanco, Carmen. (2007). Síndrome de alienación parental: efectos psicológicos. Tesis psicológicas. Recuperado del sitio de internet: http://www.redalyc.org/ articulo.oa? id=139012670007

Jurisprudencia del Tribunal Constitucional (2017). Recuperado de: http://www.tc.gob.pe/ jurisprudencia/2011/02892-2010-HC.html

Hoult, Jennifer (2006) The evidenatlly admisibility of parental alienation Syndrome: Science, Law, and Policy. Children's legal Right Journal, Vol. 26, $\mathrm{N}^{\circ} 1$, Recuperate of the site of internet: https://papers.ssrn.com/sol3/ Delivery.cfm/SSRN_ID910267_code642440. pdf?abstractid $=9102 \overline{6} 7 \&$ mirid $=\overline{1}$

\section{BIBLIOGRAFÍA COMPLEMENTARIA}

Fernández Espinoza, William. (2017). La alienación parental como causa de la variación de la tenencia. Revista Vox Juris. Lima, Perú: Fondo Editorial USMP. 